\title{
La publicidad en las revistas femeninas y masculinas: reflejo de los estereotipos de género
}

\section{Advertising in the Male and Female Magazines: A Reflection of Gender Stereotypes}

\author{
Flora Marín Murillo. Universidad del País Vasco \\ José Ignacio Armentia Vizuete. Universidad del País Vasco \\ María Ganzabal Learreta. Universidad del País Vasco
}

Recibido: 20-X-2009 - Aceptado: 16-XII-2009

Resumen:

A pesar de los esfuerzos que por parte de distintas instituciones se vienen realizando para fomentar políticas de igualdad, la publicidad que se inserta en las revistas femeninas y masculinas sigue reflejando los tradicionales estereotipos de género. Así, los productos que de forma mayoritaria se anuncian en uno y otro soporte difieren notablemente (cosmética, en las publicaciones dirigidas a las mujeres; relojes, en las editadas para hombres). También son distintas las estrategias utilizadas para la presentación de dichos productos. Este artículo se basa en una investigación sobre las revistas femeninas y masculinas en España financiada por el Ministerio de Ciencia e Innovación (referencia CSO2008-02971-E/SOCI).

Palabras clave:

Revistas femeninas, revistas masculinas, publicidad, género.

\section{Abstract:}

Despite the efforts made by different institutions to improve equality policies, advertising published in magazines for men and women continues to show the traditional gender stereotypes. Thus, the most advertised products in these magazines differ significantly (cosmetics, in women's magazine and watches in the men's ones). The strategies used for the presentation of those products are also different in both types of magazine. This article is based on a research about male and female magazines in Spain, financed by the Ministry of Science and Innovation (reference: CSO2008-02971-E/SOCI).

Keywords:

Women's Magazines, Men's Magazines, Advertising, Gender. 


\section{Introducción}

El fenómeno de las revistas llamadas "femeninas" ha sido objeto de estudio desde los años 90 tanto desde el ámbito académico como profesional. Autoras como Juana Gallego (1990) o Mercedes Roig (1989) son referencia obligada a la hora de aproximarse a este medio. Más recientemente los trabajos de María Garrido (2007) o Juan Plaza (2005) ahondan desde diferentes perspectivas en las claves y particularidades que sustentan estos discursos.

En el mismo sentido, aunque menos abundantes, podemos encontrar algunos trabajos que indagan en los entresijos de las revistas denominadas "masculinas", como es el caso del trabajo publicado por el Servicio de Consumo del Gobierno de Navarra en 2007, bajo el título de Análisis crítico de 8 cabeceras. Tendencias, sociales, publicidad, valores.

Si bien, las aportaciones en uno u otro sentido no son nada desdeñables y esclarecen muchos de los interrogantes que se nos podrían plantear al aproximarnos a estos modelos de comunicación, lo cierto es que los análisis comparativos en este terreno son muy escasos.

En los últimos años hemos asistido a un cambio en los roles e identidades asumidos tanto por hombres como por mujeres. Las categorías que antaño definían y posicionaban a cada sexo en función de unas claras diferencias genéricas se han ido diluyendo aunque no desapareciendo. Así, Inmaculada Martínez (2009) se hacía eco de estas contradicciones sociales y discursivas en las que la mujer se ha visto envuelta en las últimas décadas: "los medios de comunicación y concretamente la publicidad sigue siendo el espejo de la sociedad y como tal, el imaginario publicitario femenino también proyecta grandes contradicciones...” .

Otras autoras abogan por desechar viejos conceptos de género, como los que califican de "masculino" o "femenino" a los medios de los que vamos a hablar por nociones tales como "estilos de vida" que se adhieran indistintamente a un sexo $\mathrm{u}$ otro.

En este contexto, la publicidad es un elemento importante para comprender cuáles son las tendencias sociales, qué imaginarios e identidades construye y a través de qué estrategias. Este planteamiento exige fijar nuestra atención no sólo en los medios dirigidos a la mujer, sino también contrastar cuáles son las diferencias y singularidades entre medios claramente compartimentados y sesgados por el sexo del receptor.

También en los discursos publicitarios masculinos se ha tendido a buscar la representación del hombre alejado de las marcas de género, abriendo el abanico a otros colectivos anteriormente marginados. Sin embargo no siempre estas estrategias publicitarias responden a un cambio real. Como señalan Gámez, Rivas y Salmerón “ la emergente presencia de grupos sociales hasta ahora borrados y silenciados en el discurso 
publicitario actual, como pueden ser el ejemplo de Truth Calvin Klein, no es necesariamente un reconocimiento de lo que la diferencia supone, sino más bien una simple rentabilización de ésta, al tiempo que un fortalecimiento de la masculinidad hegemónica" (2004: 379).

Cuando se habla de diluir las diferencias, de sustituir conceptos de género, como la propia denominación de las revistas en "masculinas" o femeninas", por "estilos", "tipo de vida" que engloben indistintamente a hombres o a mujeres se hace indispensable un estudio comparativo de los textos tradicionalmente dirigidos específicamente a unos $\mathrm{u}$ a otros.

Este trabajo, enmarcado dentro de un proyecto de investigación más amplio subvencionado por el Ministerio de Ciencia e Innovación, pretende encarar ese reto a través de un análisis cualitativo y cuantitativo de las revistas masculinas y femeninas con mayor difusión y venta del Estado. En las tablas I y II aparece la difusión de las revistas seleccionadas durante el tiempo que se realizó la investigación.

Tabla I Difusión de las revistas femeninas españolas en 2008

\begin{tabular}{|ll|}
\hline Glamour & 239.624 \\
\hline Telva & 185.209 \\
\hline Elle & 174.092 \\
\hline Woman & 139.955 \\
\hline Cospomolitan & 136.753 \\
\hline
\end{tabular}

Fuente: OJD

Tabla II Difusión de las revistas masculinas españolas en 2008

\begin{tabular}{|ll|}
\hline FHM & 100.471 \\
\hline DT & 58.310 \\
\hline Men's Health & 59.236 \\
\hline Man & 33.280 \\
\hline GQ & 37.187 \\
\hline
\end{tabular}

Fuente: OJD

Como puede comprobarse con una somera comparación de ambas tablas, la difusión de las revistas femeninas es claramente superior a las de las masculinas (a esta últimas la OJD las agrupa en el apartado de "Estilo de vida"). Mientras todas las del primer bloque superan ampliamente los 100.000 ejemplares, en el 
segundo tan sólo FHM llega a duras penas a dicha cifra. Las ventas del resto son sensiblemente inferiores. Una de las explicaciones de este desfase (no aplicable a todos los casos, como por ejemplo a Man) consistiría en la mayor antigüedad en el quiosco, en términos generales, de las publicaciones para la mujer, lo que las dotaría de un asentamiento superior entre sus potenciales lectoras. De hecho, dos de las publicaciones masculinas seleccionadas en el estudio (las ediciones españolas de FHM y Men's Health) han visto la luz en la década actual.

\section{Metodología}

La metodología utilizada en la investigación ha sido la del análisis hemerográfico, suficientemente explicada por autores como Kayser (1974) o Wimmer y Dominick (1996). La muestra elegida para el estudio consistió en todos los números publicados por las diez revistas citadas (cinco masculinas y cinco femeninas) durante el segundo semestre (julio-diciembre) de 2008. En total se revisaron 57 ejemplares, ya que GQ, Men's Health y DT sólo editaron un número durante los meses de julio y agosto.

En estos 57 ejemplares se ha llevado a cabo un análisis cuantitativo y otro cualitativo. En el primer caso se ha medido el espacio publicitario de cada revista (porcentaje de páginas sobre la paginación total del medio). A continuación, se ha clasificado cada uno de los anuncios en 17 posibles categorías: "coches", "relojes", "moda”, "bebidas sin alcohol”, "bebidas alcohólicas”, “cosmética”, "gafas”, “tecnología”, “autopromoción”, “telefonía móvil”, “turismo/hoteles”, “accesorios”, “joyas”, “alimentos”, "pequeños electrodomésticos" y "otros".

Se ha llevado a cabo una comparativa entre el tipo de publicidad que inserta cada revista, confrontando las posibles diferencias existentes entre las publicaciones dirigidas al público femenino y al masculino.

Al mismo tiempo, se ha realizado un análisis de tipo cualitativo incidiendo no sólo en los productos publicitados, sino en las fórmulas de presentación utilizadas por los anunciantes para cada tipo de revista (presencia mayoritaria de mujeres en los anuncios dirigidos a los hombres, por ejemplo).

\section{Análisis cuantitativo: contenidos y espacios}

La publicidad en este tipo de revistas tiene una presencia que trasciende los límites de los anuncios ostentosamente insertados en sus páginas. Dónde termina la información y comienza el anuncio descarado de las bondades de tal o cuál producto no es un asunto fácil de dilucidar. 
Este tipo de publicaciones se nutre de la publicidad tanto para aumentar sus ingresos como para engordar sus contenidos. Ni las recomendaciones de los trucos de maquillaje de esta temporada o del coche más seguro escapan a la presencia manifiesta de marcas y productos.

Según Infoadex, la inversión publicitaria total en revistas en España durante 2008 fue de 617,3 millones de euros, tal y como puede apreciarse en la tabla III. Este volumen fue ligeramente inferior al de la radio, aunque todavía se mantuvo por delante del destinado a Internet. La crisis se dejó notar en el sector y, salvo en el caso de Internet, los anunciantes recortaron sus inserciones en todos los soportes. En el caso de las revistas el descenso publicitario fue del $14,5 \%$. Se da la circunstancia de que, al contrario de lo que había venido sucediendo en los últimos seis años, en 2008 la radio sobrepasó a las revistas como destino preferente de los anunciantes.

Tabla III Inversión publicitaria en medios convencionales en España en 2008

\begin{tabular}{|lrr|}
\hline Medio & Inversión & \% Variación 2007 \\
\hline Diarios & $1.507,9$ & $-20,4$ \\
\hline Dominicales & 103,9 & $-22,2$ \\
\hline Revistas & 617,3 & $-14,5$ \\
\hline Radio & 641,9 & $-5,3$ \\
\hline Cine & 21,0 & $-45,4$ \\
\hline Televisión & $3.082,1$ & $-11,1$ \\
\hline Exterior & 518,3 & $-8,8$ \\
\hline Internet & 610,0 & 26,5 \\
\hline
\end{tabular}

Fuente: Infoadex

El porcentaje de espacio que las revistas femeninas dedican a insertar publicidad oscila entre el 37\% de Elle y el 23\% de Woman. Si comparamos las ventas de las diferentes publicaciones, es fácil comprobar que no existe una correspondencia exacta entre este dato y el porcentaje que las revistas dedican a la publicidad. 
Tabla IV Porcentaje de publicidad en las revistas femeninas

\begin{tabular}{|lccccc|}
\hline & Glamour & Cosmopolitan & Elle & Telva & Woman \\
\hline PUBLICIDAD & $26 \%$ & $31 \%$ & $37 \%$ & $33 \%$ & $23 \%$ \\
\hline CONTENIDOS & $74 \%$ & $69 \%$ & $63 \%$ & $77 \%$ & $67 \%$ \\
\hline
\end{tabular}

Glamour que en el año 2008 era la de mayor difusión, se queda en cuarta posición en cuanto al porcentaje de publicidad inscrito en sus páginas. Esto no quiere decir que en sus ingresos por anuncio ocupe también esta posición ya que sus tarifas también pueden diferir del resto.

Las revistas masculinas tienen unos porcentajes más bajos en consonancia con su difusión. Tan sólo FHM, con 100.471 ejemplares vendidos, se acerca a sus homólogas femeninas.

Tabla V Porcentaje de publicidad en las revistas masculinas

\begin{tabular}{|lccccc|}
\hline & Man & FHM & GQ & Men`s Health & DT \\
\hline PUBLICIDAD & $14 \%$ & $18 \%$ & $23 \%$ & $22 \%$ & $20 \%$ \\
\hline CONTENIDOS & $86 \%$ & $82 \%$ & $77 \%$ & $78 \%$ & $80 \%$ \\
\hline
\end{tabular}

GQ es la única revista masculina que alcanza el 23\%, equiparable al porcentaje más bajo de las femeninas, ostentado por Woman.

Hay que tener en cuenta que este tipo de publicaciones surgen más recientemente (GQ aparece en 1994) en busca de un segmento de la población masculina potencialmente interesado por aspectos que tradicionalmente habían estado restringidos al universo femenino.

\section{Los contenidos publicitados}

\subsection{De mujer a mujer: la publicidad en las revistas femeninas}

En las revistas femeninas la cosmética, la moda, joyas y accesorios se sitúan en los primeros puestos del ranking. La cosmética está a la cabeza en casi todas ellas, variando ligeramente los porcentajes como se puede ver en la figura 1 . 


\section{Figura 1 Cosmética en las revistas femeninas}

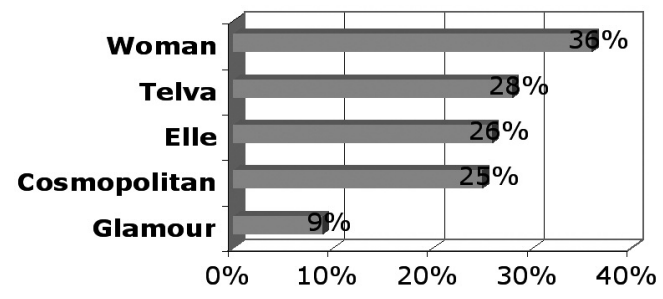

Como señala Meritxell Roca (2006) estas revistas pretenden ser una especie de guía para las mujeres y "la belleza equiparada a la juventud es uno de los ejes principales de dichas publicaciones".

Sólo en Glamour los anuncios de moda y colonias están muy por encima con un $22 \%$ y 21\% respectivamente. No en vano la cabecera de la revista va acompañada del eslogan "La revista internacional de moda más vendida en España”.

Figura 2 Publicidad en Glamour

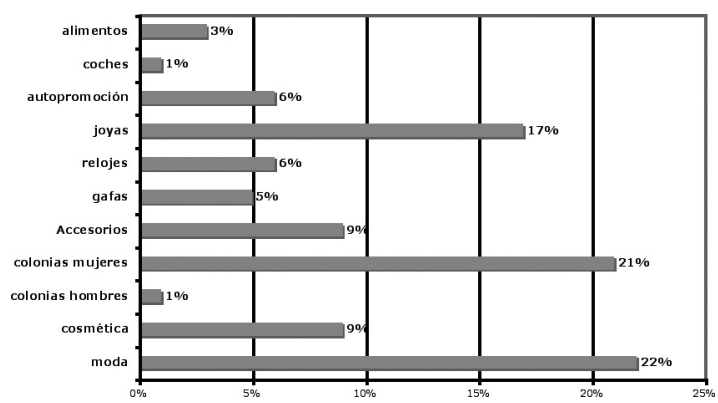

Figura 3 Publicidad en Woman

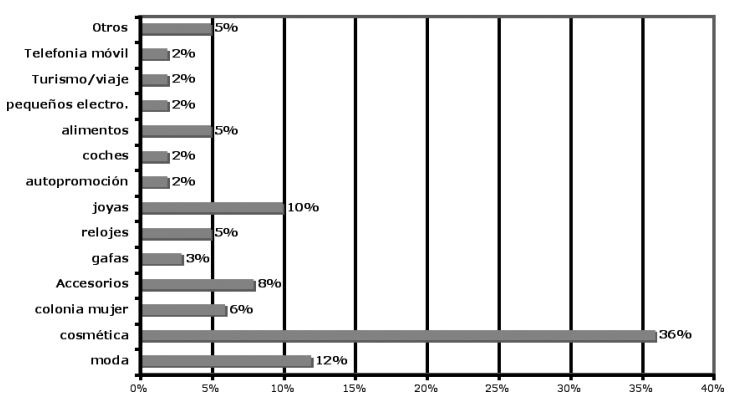

En el resto, la moda ocupa el segundo puesto, con unos porcentajes que oscilan entre el $12 \%$ y el $15 \%$. No deja de ser curioso que unas publicaciones que se definen a sí mismas como revistas de moda no tengan en este tipo de publicidad su mayor fuente de ingresos. Sin embargo al hojear cualquiera de ellas notamos cómo la moda en forma de reportaje fotográfico, entrevista a modistas, modelos y actrices, se convierte en el tema prioritario de la mayoría de ellas. Sin olvidar las alusiones directas a marcas, productos y firmas de prestigio, es decir publicidad más o menos encubierta. Así como secciones como "escaparate", "compras" o "guía de compras", donde las marcas y sus precios se exhiben sin complejos. 
El resto de los anuncios se distribuye de manera desigual entre los "accesorios" (zapatos y bolsos), "joyas", "relojes”, “colonias”, “gafas”, “coches”, “telefonía móvil”, “turismo/hoteles”, “tecnología”, “alimentos”, "pequeños electrodomésticos”, “autopromoción”, “bebidas alcohólicas”, "bebidas sin alcohol” y “otros”

El apartado "joyas" destaca por su alto porcentaje, si bien en él incluimos tanto las joyas propiamente dichas como las marcas de alta bisutería. Evidentemente este tipo de revistas, calificadas por algunas autoras como de "alta gama", tienen un target de mujeres de clase media-alta, a las que se les presupone suficiente poder adquisitivo como para aspirar a comprarse una joya sin esperar a que se las regalen hijos, novios, o maridos.

Los anuncios de colonias y perfumes tienen una relevancia desigual dependiendo de la publicación. Así, en Cosmopolitan igualan a los cosméticos con un 25\%, en Glamour ocupan un 22\% del espacio publicitario y, ya más alejados, están Elle con un 14\% y Telva y Woman con un 7\% y un 6\% respectivamente. Excepcionalmente aparecen algunos anuncios de perfumes destinados a los hombres, como ocurre con "Versace" o "Boss".

Figura 4 Publicidad en Elle

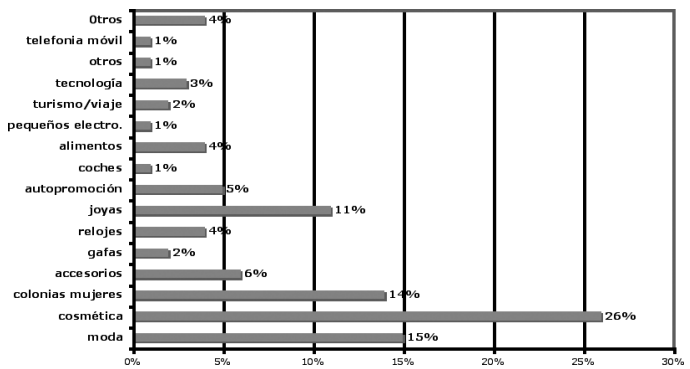

Figura 5 Publicidad en Telva

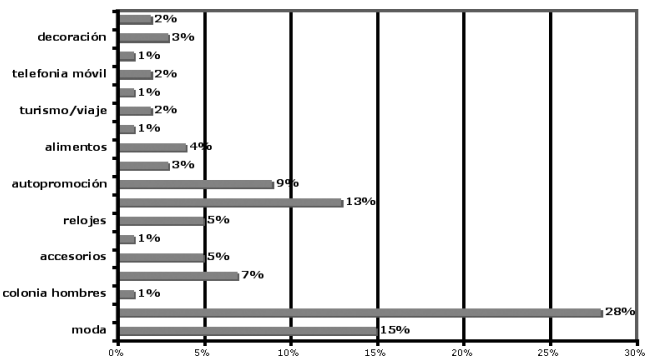

Las gafas y los relojes han sido ubicados en categorías distintas a la más genérica de "accesorios" para reflejar así lo significativo de su presencia, no tanto en estos medios, entre $5 \%$ y un 1\%, pero sí en las publicaciones masculinas, como más adelante veremos.

Las gafas sobre todo son publicitadas en muchos casos como productos que sirven de estandarte y recordatorio de unas firmas y marcas de prestigio que trascienden al objeto mismo, así ocurre con Carolina Herrera, por ejemplo.

Los "pequeños electrodomésticos" están presentes en Cosmopolitan, Telva y Woman y son planchas para el pelo, secador, ultraestimulador, aparato para lipomasaje, etc. Todos estos artículos están asociados al em- 
bellecimiento de la consumidora y ninguno, a excepción de una lavadora publicitada en Elle y evidentemente no incluida en esta categoría, a los quehaceres cotidianos del ama de casa.

\section{Figura 6 Publicidad en Cosmopolitan}

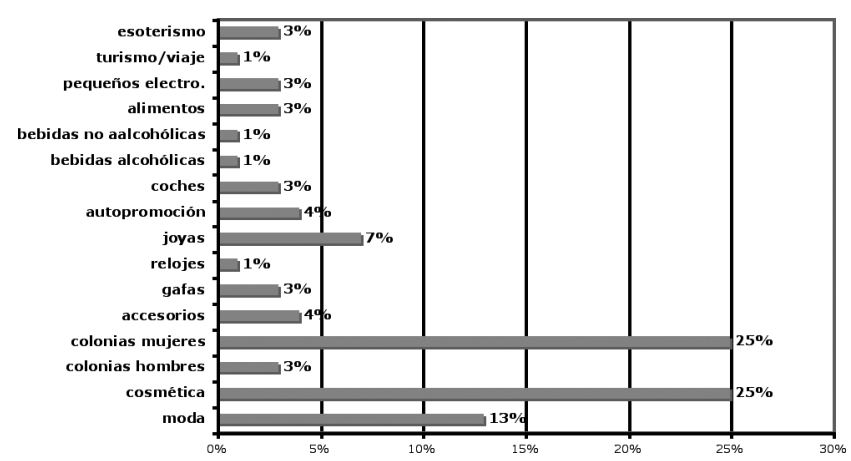

Otra categoría con una presencia más o menos anecdótica es la de "alimentos", donde nos encontramos con anuncios de bombones (Ferrero Roche y Valor), aceitunas y Vitaline. Son de sobra conocidos los tópicos que asocian a la mujer con el consumo de chocolate, alimento compensador y sustituto de todo tipo de carencias y frustraciones.

Vitaline, no es sólo un producto nutritivo sino que sus particulares propiedades se asocian a la salud de manera directa. Más difícil de justificar sería la presencia de las aceitunas, aunque evidentemente no se trata de un producto para llenar la cesta de la compra sino un aperitivo que nos remite directamente al ocio y el tiempo libre.

En cualquier caso ninguno de los productos mencionados serviría para alimentar a una familia, ni se prestaría a ser cocinado. Se trata más bien de complementos alimenticios que, en el caso sobre todo de las aceitunas y los bombones, son asociados a momentos de disfrute y ocio, lejos de las rutinas cotidianas de la abnegada ama de casa.

El apartado de "autopromoción" en sus diversas versiones: suscripciones, concursos, regalos sorpresa, o publicidad de otras revistas de la misma editorial, está en todas ellas. Sus porcentajes oscilan entre el escaso $2 \%$ de Woman y el $9 \%$ de Telva.

Si examinamos los contenidos de la publicidad de cada una de estas revistas veremos como frente a una generalizada homogeneidad se atisban pequeños matices. De entre todas las revistas femeninas, Telva es la 
que mayor variedad de contenidos presenta, junto a las categorías antes mencionadas, cabe resaltar la dedicada a decoración, ya que es la única publicación que incluye anuncios de esta gama. Así como un mayor porcentaje de alimentos, $4 \%$, y una gran variedad de anuncios incluidos en la categoría "otros", que van desde la ayuda solidaria, La esfera de los libros (perteneciente al mismo grupo editorial de Telva) o el Banco de Santander

Cosmopolitan aporta la particularidad de incluir pequeños anuncios, cromos, que se distribuyen en los laterales de la sección de "Guía de compras" y publicitan los servicios de un surtido grupo de videntes y pitonisas.

De entre todas ellas ésta es la revista que más se aleja de los parámetros que identifican a una revista de esta gama. Sus contenidos abundan en materias sexuales y las relaciones personales son tratadas en todas sus facetas y espacios, laborales, familiares, públicos o privados. Y a nivel de géneros son los que más abusan de tests, consultorios y testimonios.

\subsection{De hombre a hombre: la publicidad en las revistas masculinas}

Las revistas masculinas reparten sus contenidos publicitarios entre "coches", "relojes", "colonias", "moda", "bebidas alcohólicas”, “cosmética”, ”gafas”, “tecnología”, “autopromoción”, “telefonía móvil”, “motos”, “turismo/hoteles", “autopromoción” y "otros".

Los primeros puestos se distribuyen de forma desigual en estas publicaciones. La publicidad de bebidas alcohólicas está a la cabeza en MAN con un 20\% y las colonias son las más publicitadas en FHQ y Men's Health, ambos con un 20\% de ocupación, sin olvidar el 22\% de GQ que iguala al 22\% de anuncios de relojes en la misma revista.

Figura 7 Publicidad en GQ

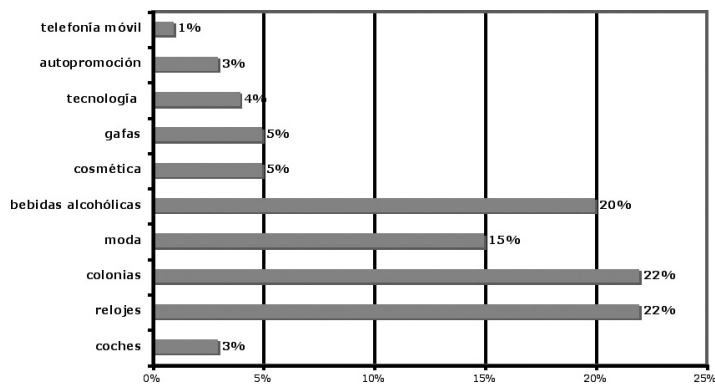

Figura 8 Publicidad en $D T$

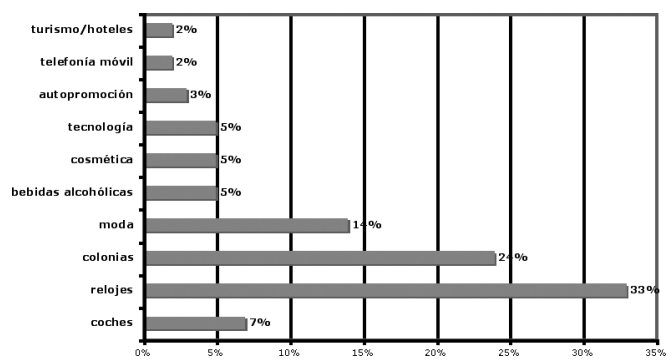

$44\left|n^{\circ} 10\right|$ doxa.comunicación 
También son los anuncios de relojes los que mayor presencia tienen en DT con un 33\%. Al igual que ocurría con las revistas femeninas en sus homólogas masculinas encontramos algunos matices que pasamos a detallar:

En GQ advertimos un gran equilibrio entre categorías tales como "relojes" con un $22 \%$, "colonias "un $22 \%$ también, "bebidas alcohólicas" 20\% y "moda” un 15\%. Se puede decir que los productos estrella en esta publicación sobresalen del resto de las categorías cuya presencia oscila entre el 5\% cosmética y gafas y el 1\% de telefonía móvil.

DT centra su atención en "relojes" con el porcentaje más alto de las cinco publicaciones, un 33\%, y “colonias" y "moda”, con un $24 \%$ y $14 \%$ respectivamente.

Figura 9 Publicidad en Man

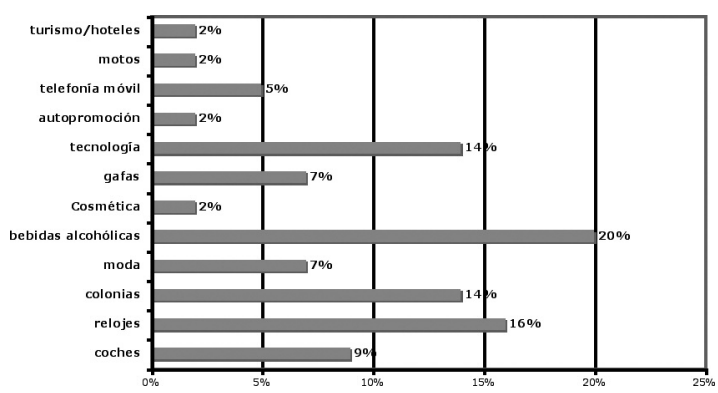

Figura 10 Publicidad en FHQ

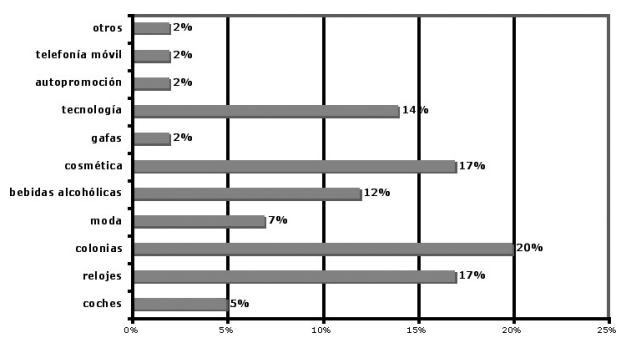

Los "coches" serían la siguiente categoría a destacar alcanzando apenas un 7\%. El resto del espacio se distribuye de manera desigual entre el $2 \%$ de "turismo/hoteles" y “telefonía móvil” y el 5\% “cosmética” y "bebidas alcohólicas”. Este último porcentaje llama la atención, ya que entre las cinco revistas analizadas, esta es la que menos publicidad de bebidas alcohólicas inserta en sus páginas, apenas 3 ó 4 anuncios por número.

Todo lo contrario sucede con la revista $M A N$, donde la publicidad de bebidas representa el 20\% del espacio publicitario, seguido de cerca por los relojes $16 \%$, colonias $14 \%$, tecnología también con un $14 \%$ y coches con un $9 \%$. Destaca la acentuada presencia de la "tecnología” en sus páginas con un porcentaje que sólo es igualado por la revista FHQ. En esta categoría se incluyen ordenadores, televisores, cámaras de fotos y videojuegos. 
Figura 11 Publicidad en Men's Health

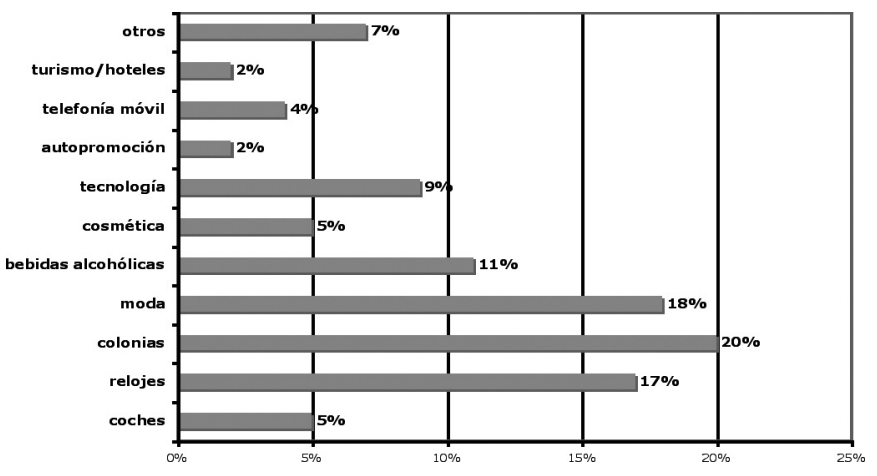

En FHQ además de la "tecnología”, resalta respecto al resto de las publicaciones la importancia de la "cosmética” que llega a ocupar el segundo puesto en compañía de los relojes también con un 17\%.

En ninguna otra revista la "cosmética" alcanza un nivel tan alto y, aunque en este concepto incluimos los tradicionales after shaves, también las cremas anti-envejecimiento están cada vez más presentes.

Men's Healt 'h se mueve en los parámetros conocidos con porcentajes altos en las categorías más usuales: “colonias” 20\%, "bebidas alcohólicas” 18\% y “relojes” con un 17\%. Destaca por ser la publicación que publica más anuncios de moda, un 18\%, en consonancia con los contenidos de la revista.

\section{Análisis comparativo}

De lo anteriormente expuesto se desprende que tanto las revistas femeninas como masculinas tienen muy claro el público al que se dirigen y la publicidad aprovecha esta segmentación de la audiencia para exponer unos anuncios claramente orientados según categorías e intereses.

La publicidad no es muda y a través de ella se habla de los intereses de la sociedad, de los gustos, sueños e inquietudes de un grupo o una colectividad. Podríamos pensar que esta publicidad no conoce sexos, ni distingue entre clases sociales ni status ni poder adquisitivo. Pero nada más lejos de la realidad. Podríamos pensar que abandonados viejos parámetros de género, la publicidad se acomoda a los cambios y se dirige por igual a hombres y mujeres variando sólo en función de los estilos de vida que unos u otros adopten indistintamente. Pero también en esto último aparecen contradicciones. 
Una vez expuestas las particularidades de cada publicación en función de la audiencia a la que van dirigidas vamos a comparar cuáles son sus similitudes o diferencias cuando contrastamos los datos generales de ambos medios.

Tabla VI

\begin{tabular}{|lcc|}
\hline & Revistas masculinas & Revistas femeninas \\
\hline coches & $5,4 \%$ & $1,8 \%$ \\
\hline relojes & $21,9 \%$ & $4,6 \%$ \\
\hline colonias & $20,8 \%$ & $14,7 \%$ \\
\hline moda & $11,9 \%$ & $15,2 \%$ \\
\hline bebidas sin alcohol & & $0,2 \%$ \\
\hline bebidas alcohólicas & $13,6 \%$ & $0,4 \%$ \\
\hline cosmética & $6,5 \%$ & $25,1 \%$ \\
\hline gafas & $2,9 \%$ & $2,8 \%$ \\
\hline tecnología & $8,2 \%$ & $1,2 \%$ \\
\hline autopromoción & $2,5 \%$ & $5,9 \%$ \\
\hline telefonía móvil & $2,5 \%$ & $1,0 \%$ \\
\hline turismo/hoteles & $1,1 \%$ & $1,6 \%$ \\
\hline accesorios & $1 \%$ & $6,1 \%$ \\
\hline joyas & & $11,9 \%$ \\
\hline alimentos & & $3,8 \%$ \\
\hline pequeños electro. & $1,8 \%$ & $1,0 \%$ \\
\hline otros & & $2,8 \%$ \\
\hline \hline
\end{tabular}


Figura 12 Contenidos publicitarios en las revisas femeninas y masculinas

Contenidos publicitarios en las revistas femeninas y masculinas

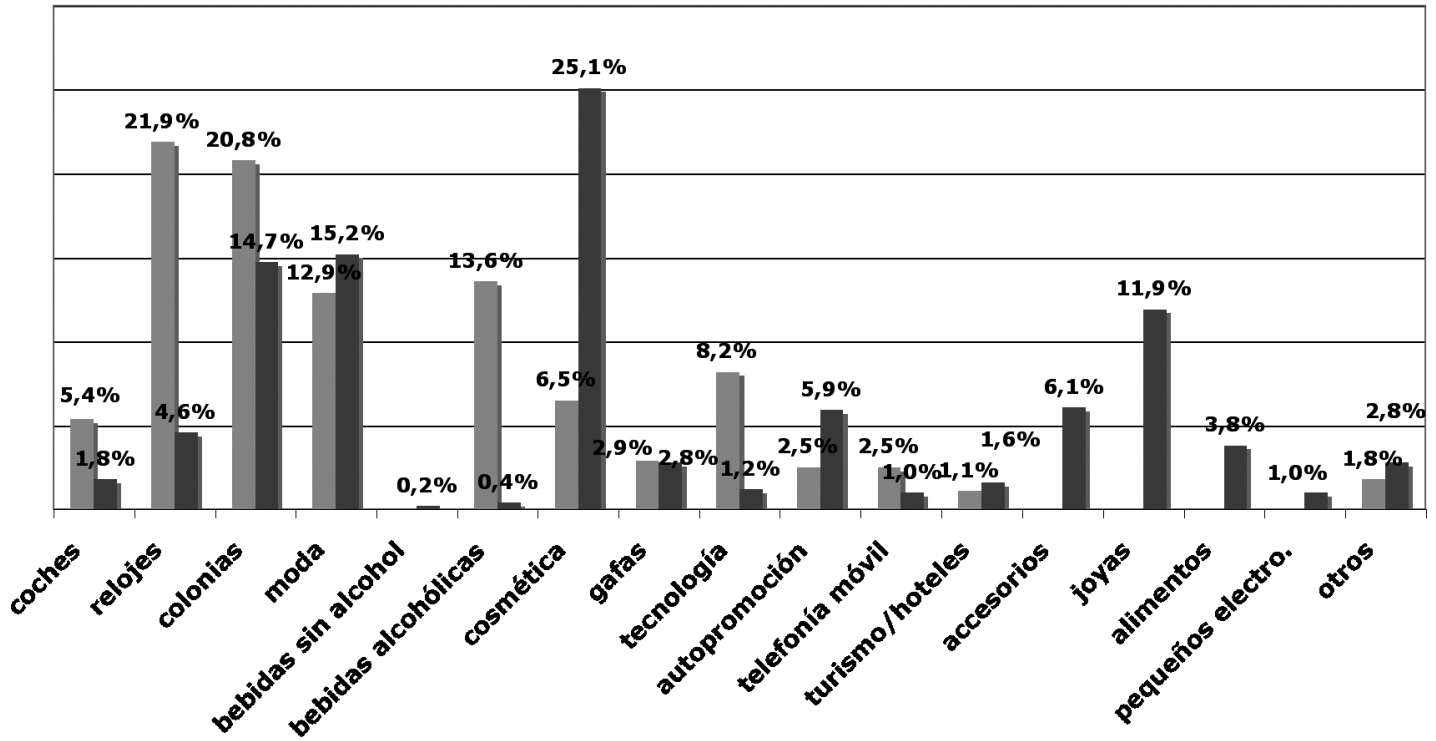

Si reparamos en los datos de la tabla VI y de la figura 12, lo primero que nos llama la atención son las ausencias. Si nos fijamos en el gráfico hay una serie de categorías que aparecen sólo en las revistas femeninas: joyas, pequeños electrodomésticos, alimentos y bebidas sin alcohol.

Los pequeños electrodomésticos son, en general, de uso marcadamente femenino: planchas para el pelo, secador, ultraestimulador, aparato para lipomasaje, etc. Todos ellos se asocian al cuidado del cuerpo y embellecimiento de la mujer. Aunque evidentemente podrían tener un uso masculino.

Los anuncios de joyas para la mujer no tienen cabida en las revistas masculinas, lo cual también llama la atención, ya que las joyas (de alta gama o bisutería) se asocian generalmente con fechas señaladas, cumpleaños, aniversarios, navidades, etc. La creencia popular es que el hombre con motivo de tan señaladas fechas regala a la madre, novia, esposa o compañera, una de esas joyas. Sin embargo, la inserción de esos productos exclusivamente en las revistas dirigidas a la mujer parecen desdecir semejante creencia.

Estamos ante una mujer con poder adquisitivo, independiente y capaz de elegir y adquirir por sí misma los caprichos que estén a su alcance, entre ellos las joyas, sin necesidad de esperar ser objeto de la atención mas- 
culina. Esta sería una hipótesis, o también puede ser que el anunciante sepa que es a la mujer a la que debe dirigirse pues esta apreciará el atractivo de la joya y o bien la adquirirá directamente o la pedirá expresamente como regalo. En cualquiera de los casos se sobreentiende que es a ella a quien hay que convencer.

Otra ausencia destacable es la de los alimentos, aunque en el caso de las revistas femeninas apenas alcancen un 3,8\% e incidan en algunos estereotipos marcadamente femeninos. Mayoritariamente se publicitan bombones, dando por bueno el tópico de que la mujer es más golosa que el hombre. Otro tanto ocurre con los yogures "Vitaline" que, según anuncian, ayudan a regular el tránsito intestinal.

Las bebidas con o sin alcohol son otro de los elementos diferenciadores. Según el informe Encuestas domiciliarias sobre Alcohol y Drogas en España 2007/2008, presentado por el Observatorio español sobre drogas del Ministerio de Sanidad y Consumo (http://www.pnsd.msc.es/Categoria2/observa/estudios/home.htm), la digesta de alcohol está más extendida entre hombres, sobre todo cuando se trata del consumo diario. Sin embargo, estas diferencias se atenúan en los casos de consumo anual o mensual: "Así, por ejemplo, el cociente de prevalencias hombre/mujer fue sólo de 1,2 para la prevalencia anual de consumo, de 2,1 para la prevalencia anual de borracheras, de 1,5 para la prevalencia mensual de consumo, de 2,7 para la prevalencia mensual de consumo de 5 vasos o más en alguna ocasión....”.

Desde luego estas diferencias en el consumo por sexos no están reflejadas en la publicidad. El 13,2\% que media entre la publicidad de alcohol insertada en las revistas de mujeres $(0,4 \%)$ y la de hombres $(13,6 \%)$, abre un abismo que nada tiene que ver con la realidad. Aunque hay que hacer notar que las bebidas más publicitadas para las mujeres son el whisky y la ginebra, bebidas asociadas tradicionalmente al consumo de los varones.

El 0,2\% de los anuncios de bebidas sin alcohol que aparecen en las publicaciones femeninas y la ausencia de las mismas en las masculinas resulta un hecho casi anecdótico, pero refleja cómo ellas son aprehendidas como sus únicas consumidoras potenciales.

Otra diferencia notable la encontramos en la categoría de "cosméticos" donde las revistas femeninas parecen ser el escaparate perfecto con un 25,1\%, encabezando la lista de productos más publicitados.

Hay que tener en cuenta que en España la industria cosmética alcanzó en 2007 un consumo de 7.872 millones de euros, con un crecimiento 5,67\% respecto al año anterior. En 2008, en plena crisis económica los sectores de belleza e higiene incrementaron sus gastos en un 7,4\% de enero a septiembre, mientras el resto de los sectores se encontraban en una clara recesión. (El Mundo 1/2/2009: "Belleza y cosmética, 'niñas bonitas' de la inversión"). 
Para Jiménez, Delgado y Ramos a pesar de las transformaciones que se han producido en la mujer, mayor autonomía laboral, política, familiar y sexual; el cuidado de la belleza sigue siendo una tendencia en constante crecimiento en nuestra sociedad. "Esta estrategia de crecimiento ha sido motivada, en mayor medida, por el cambio social que aún se está produciendo en el entorno femenino. Esto es, las transformaciones sociales han dado lugar a nuevos públicos, primordialmente femeninos, destino directo de nuevos estilos de vida, moda y belleza" (2006: 61).

En las revistas masculinas, la cosmética no supera el 7\%, y aunque su presencia no es en absoluto equiparable a la de las publicaciones femeninas, se observa también una tendencia al alza respecto a etapas anteriores.

El culto al cuerpo, la mitificación de la belleza y la eterna juventud son valores que si hasta hace poco eran exclusivos del ámbito femenino, en los últimos años se están filtrando en el imaginario masculino. Resulta esclarecedor a este respecto constatar cómo las colonias y perfumes en las publicaciones masculinas ocupan ya un 14,7\% del espacio y acortan distancias respecto al 20,8 \% de sus homólogas femeninas.

"El perfume se ha convertido en un artículo de lujo, que hoy en día cada mujer se puede permitir. Se trata de un artículo que no está ligado a una cultura determinada, sino que es consumido por mujeres en todo el globo, pero, a su vez, el uso de una fragancia está ligado íntimamente a la personalidad de la mujer que lo lleva" (Montes, 2006: 217). A tenor de lo dicho, la importancia que adquiere la presencia de estos productos también en los medios dirigidos a hombres nos permite vislumbrar cuáles están siendo las transformaciones de la masculinidad y del género en estas publicaciones.

La moda sería otra de las categorías que junto a las colonias y la cosmética representan no sólo el grueso de la publicidad en las revistas femeninas sino también los puntos clave de coincidencia respecto a las masculinas. Las diferencias se acortan en esta categoría, donde las publicaciones masculinas alcanzan un 11,8\% y las femeninas un $15,2 \%$.

Aunque, según Tseelon (1997), a lo largo de la historia, las vanidades del vestir a través de discursos que van desde la teología hasta la moda hayan contribuido a definir a las mujeres como banales, superficiales, triviales e incluso malvadas lo cierto es que el hombre poco a poco se va impregnando también de estos discursos y comienza a ser víctima de los mismos.

Llama poderosamente la atención el 21,9 \% del espacio publicitario que es dedicado a los relojes masculinos. Si bien las revistas femeninas también dejan un hueco a esta categoría, 4,6\%, está muy lejos de encabezar el ranking publicitario. 
Los anuncios de relojes son los reyes de la publicidad dirigida al hombre por encima de cualquier otro producto. Si buscamos algún tipo de paralelismo podríamos decir que son a los hombres lo que las joyas representan para las mujeres.

La mayoría de los españoles cuenta con dos relojes, ya que, al igual que los accesorios femeninos, ha de elegirse el apropiado para cada ocasión. Fernando Zher, director general de Tag Heuer en España, auguraba en las páginas de El Mundo (Magazine, 27/4/2003), para el futuro inmediato un mayor número de unidades por consumidor. "Los relojes -decía- cada vez están más integrados al ámbito de la indumentaria, y el mercado demanda de la industria una mayor especialización para cubrir diferentes aspectos de la vida: el trabajo, los eventos sociales, las vacaciones... Para cada momento hay un modelo a la medida”. Además, el reloj de pulsera ha perdido parte de su función práctica para convertirse en un guiño de identidad, en un "dime qué reloj llevas y te diré cómo eres".

Otros accesorios como las gafas son representados de manera muy similar en ambos medios, alrededor del $3 \%$.

Por supuesto la categoría específica de "accesorios" está pensada sobre todo para la prensa femenina pues engloba zapatos y bolsos, de ahí que alcance un $6,1 \%$ y apenas un $1 \%$ en las masculinas.

Otra categoría en la que los datos se resuelven a la inversa es en la denominada “tecnología”. Ahí los hombres parecen ser los únicos interesados en ordenadores, cámaras de fotos y televisores, 8,2\%, quedando reducido este espacio y consiguientemente sus intereses a un 1,2\% para las mujeres.

La “telefonía móvil” se mueve todavía dentro de unos parámetros relativamente bajos, pero llama la atención que sus cifras se dupliquen en el caso masculino con un 2,5\%.

Y por último un producto que parece tender a una cierta homogeneización son los coches tanto cualitativa como cuantitativamente. Aunque todavía están muy por encima en las revistas masculinas 5,4\% respecto a un $1,8 \%$.

La publicidad de automóviles ha descendido en las publicaciones para hombres y va buscando un hueco en las de mujeres, donde se publicitan mayoritariamente coches pequeños pero en general sofisticados, Nissan micra, Audi 3, un mini Jeep, y un Ford fiesta.

Los coches familiares, deportivos o de alto standing son exclusivamente insertados en las revistas masculinas, aunque observamos cómo también tienen cabida anuncios de automóviles más modestos y asequibles. 


\section{Análisis cualitativo}

A nivel iconográfico hemos de decir que lo más llamativo es la coincidencia entre el sexo del personaje que publicita el producto y el destinatario del mismo. Así, en las revistas femeninas, prioritariamente son mujeres las que aparecen en los anuncios, y en las masculinas, hombres. Hay, como se puede advertir, una tendencia marcadamente narcisista en este tipo de publicidad.

En las revistas masculinas la mujer como reclamo sexual, tan frecuentemente utilizada en la publicidad televisiva, queda relegada a un segundo plano en la mayoría de los anuncios, si bien hay algunas excepciones:

La mujer como objeto erótico, apelando a su sensualidad y erotismo, está presente en los anuncios de "Baileys”. El recurso de la sinécdoque se pone en juego en todos ellos para sugerir la presencia de un cuerpo femenino que queda fuera de campo, siendo este sustituido por la sensualidad de unos labios femeninos, gruesos y oscuros, o rosados y procaces. "Listen your lips" es el eslogan de la campaña, y la mujer de nuevo la promesa de la misma.

También esporádicamente, la mujer se funde con el producto hasta parecer un embrión del mismo. Así surge Paz Vega como una Venus renacida de la pantalla de una televisión Samsung Cristal, donde la pantalla y el vestido de la protagonista sugieren la misma textura y belleza cristalina.

Aquellas fragancias que tienen sendas versiones para hombres y mujeres también incorporan a ambos sexos en su publicidad. Este es el caso de los anuncios de "Hugo Boss".

Marginales resultan aquellos anuncios donde la presencia de la mujer junto al hombre toca de nuevo los resortes más conocidos. "Kenzo Power", por ejemplo se anuncia a través de una composición en la que un primer plano de un hombre ocupa la mitad de la parte derecha de la página. A su izquierda, al fondo y difuminada se recorta la figura de una mujer desnuda. Ella está de espaldas y él no la mira.

Menos sutiles son los anuncios de "Hugo Boss", donde una pareja de jóvenes vestidos de negro, se asen de la cintura mientras se miran intensamente.

"Versace" publicita su fragancia mostrando a una pareja que se abraza. Ella desnuda, él con la camisa abotonada. Él interpela directamente al lector a través de su mirada, mientras ella entregada cierra los ojos ante la promesa de un nuevo beso. Este es un claro ejemplo de puesta en escena donde el hombre es el dominante y la mujer la dominada. Él seguro de sí mismo, y ella frágil y vulnerable, víctima de su propia pasión.

Al margen de estas excepciones el resto de la publicidad tiene como protagonista al producto, primeros planos de relojes, ordenadores, coches, o al hombre solo o acompañado de otros hombres. 
En general se trata de hombres jóvenes, apuestos y elegantes que interpelan al lector, a veces directamente, otras de soslayo, pero siempre expresando cierta complicidad.

Jean Paul Gautier gusta de mostrar jóvenes efebos, con los torsos desnudos, o con camisetas marineras y hombros tatuados. El escenario es un baño y ellos aparecen recostados sobre el lavabo o mirándose al espejo en una actitud de plácido abandono.

En las revistas femeninas se invierte la proporción y mayoritariamente son mujeres solas, jóvenes, atractivas, aniñadas, apasionadas o virtuosas, las que venden moda, perfumes, o cosméticos. Las imágenes remiten a todos los estereotipos conocidos, la femme fatal, Venus, la sirena, Eva, Lolita, etc. En muy pocas ocasiones hay presencia masculina y cuando es así la actitud del hombre es siempre más protectora y condescendiente. Así en "Nivea Visage", los labios de un hombre parecen rozar la nuca de una mujer que sonriente y cabizbaja se somete gustosa a la adulación masculina.

Para los relojes "Breil Tribe" se construye un escenario donde parejas dispersas en diferentes planos se muestran en actitudes románticas y cariñosas. El lazo que les une no es sólo la actitud romántica sino el reloj que todas las mujeres portan.

Más impactante es sin duda el anuncio de la línea de alta joyería “Dyblos”, donde un Ángel desnudo porta en sus brazos a una mujer también desnuda, cuyo único aderezo es un gran collar negro. La puesta en escena remite claramente al tema iconográfico de La Piedad, aunque los roles sexuales estén en esta ocasión invertidos. De nuevo el hombre como ángel protector tiene en sus manos la vida de una frágil mujer.

Tanto en la prensa masculina como femenina se recurre a figuras de prestigio para revalorizar la marca, aunque abundan más en éstas últimas. Las actrices Paz Vega y Penélope Cruz, la cantante Raquel del Rosario, el arquitecto Fukuda Makoto, o el actor Matthew McConaughey son algunos de los personajes elegidos.

\section{Conclusiones}

Juana Gallego (2007: 170) aboga por la desaparición del término revista femenina ya que no existe un único modelo de mujer, sino múltiples posibilidades. Además, según esta autora, no hay una moral para ellos y otra para ellas, ni valores diferentes. "Con esta nueva nomenclatura se eliminarían incoherencias teóricas y metodológicas, al mismo tiempo que representaría una nueva concepción de los sexos en la sociedad actual. Sería dar reconocimiento a que los géneros han evolucionado y que ya no es tan determinante ser hombre o ser mujer para llevar a cabo los proyectos de vida individual". 
Si bien podemos estar de acuerdo con estas afirmaciones a un nivel general creemos que a la luz de nuestro análisis los cambios se están produciendo pero todavía resulta difícil obviar las diferencias.

Del análisis de la publicidad en ambos tipo de revistas se desprenden fundamentalmente las tres siguientes conclusiones:

a) El culto al cuerpo y la belleza son valores en alza en el universo masculino que se aproxima de esta manera a la imagen social que de la mujer tradicionalmente se ha tenido. Coinciden con ellas en su gusto por los perfumes, y aunque no alcanzan sus cuotas de consumo, se ven cada día más seducidos por la cosmética y la moda. El porcentaje que se dedica a categorías como "colonias" (14,7\%), "cosmética" (7\%) o "moda" $(11,8 \%)$ así lo atestiguan.

Aunque las mismas referencias en las revistas femeninas, "colonias" (20,8\%), "cosmética” (25,1\%), "moda” (15,2\%), estén todavía por encima es evidente que las distancias se acortan.

b) Son muchos todavía los productos que, dependiendo del género, son excluidos de la publicidad de uno u otro tipo de revista. Así, atendiendo a los productos publicitados, las mujeres apenas beberían $(0,4 \%)$, ni comprarían aparatos electrónicos, como ordenadores, televisores o videojuegos (1,2\%). Aunque tienen poder adquisitivo no tienen peso a la hora de elegir el coche familiar, y se limitarían a buscar entre modelos pequeños aquel más coqueto $(1,8 \%)$.

Son compradoras de pequeños electrodomésticos (1\%) siempre y cuando estos tengan que ver con su cuidado personal: planchas para el pelo, secadores, etc., y si acaso algún electrodoméstico de mayor tamaño se cuela en sus páginas, este es una lavadora. Se dejan seducir por las joyas, la alta bisutería (11,9\%), la moda $(15,2 \%)$ y los accesorios $(7,4 \%)$. Y entre todos los productos, los cosméticos $(25,15)$ son un símbolo de su búsqueda incesante de la eterna juventud.

Algunas además son adictas a todo tipo de videntes y esoterismo (ver la publicidad de Cosmopolitan), y todas ellas se alimentan de bombones, aceitunas y yogures $(3,8 \%)$ con propiedades para regular el tránsito intestinal.

Ellos, a tenor de la publicidad insertada en las revistas masculinas, beberían como cosacos todo tipo de bebidas siempre y cuando tengan alcohol (13,6\%), no olvidemos que todas las contraportadas de las revistas masculinas tienen un anuncio de licor. Las mujeres, como vimos, son las únicas receptoras de la publicidad de bebidas sin alcohol $(0,2 \%)$. 
Los varones son consumidores de todo tipo de artilugios electrónicos (8,2\%), así como de telefonía móvil. Los relojes son para ellos como las joyas para las mujeres. Se trata del accesorio más publicitado en sus páginas $(21,9 \%)$ y va más allá de su valor utilitario para convertirse en un complemento imprescindible, en un símbolo de distinción y buen gusto.

La elección del coche, familiar o no, queda en sus manos (5,4\%), y aunque esta categoría ha ido descendiendo en los últimos años, la prensa masculina continúa siendo líder de la misma.

c) Los estilos de vida masculinos y femeninos tienden a encontrarse pero desde luego no se confunden. La publicidad se dirige a sexos y no a personas, identificando con éstos determinados productos y excluyendo otros.

Curiosamente en ambos modelos de publicación la imagen del hombre o la mujer sola es la más recurrente, aunque cuando aparecen en compañía, excepto alguna excepción, siempre lo hacen como seductores, protectores y conquistadores de mujeres generalmente más débiles y vulnerables que ellos.

Por todos estos motivos nos parece evidente que si bien mujeres y hombres pueden llegar a ser definidos en un futuro en función de sus estilos de vida independientemente de su sexo, todavía hoy en día la publicidad, reflejo y constructor a la vez de imaginarios colectivos e identidades sociales, no termina de moverse dentro de esos parámetros.

\section{Referencias bibliográficas}

Asociación Plaza del Castillo de Usuarios de Medios de Comunicación (2007): Análisis crítico de 8 cabeceras. Tendencias, sociales, publicidad, valores. Pamplona: Servicio de Consumo del Gobierno de Navarra.

El Mundo, 1/2/2009 “Belleza y cosmética, 'niñas bonitas' de la inversión”.

Gallego, J. (2007): “La prensa femenina: una cala de difícil abordaje”, en Fernández, J. J.: Prensa especializada actual. Madrid: Mac Graw Hill, pp. 131-175.

- (1990): Mujeres de papel: de “Hola” a "Vogue”. La prensa femenina en la actualidad. Barcelona: Ariel.

Gámez, M. J; Rivas, A. M. y Salmerón, P. (2004): “La masculinidad embotellada: la publicidad de perfumes masculinos ante los nuevos discursos sociales”, en VV. AA.: La comunicación: nuevos discursos y perspectivas. Madrid: Edipo, pp. 375-380.

Garrido, M. (2007): Los rasgos temáticos y de estilo propios del periodismo de servicio en las revistas femeninas de alta Gama. Tesis doctoral. Universidad Pontificia de Salamanca.

Kayser, J. (1974): El diario francés. Barcelona: ATE. 
Infoadex (2009): Estudio Infoadex de la inversión publicitaria en España 2009. Madrid: Infoadex.

Jiménez, G.; Delgado, M. y Ramos, M. (2006): “Clinique: el medio gráfico como estrategia publicitaria en el sector de la perfumería y la cosmética", FISEC-Estrategias. Revista académica del Foro Iberoamericano sobre Estrategias de Comunicación. Año 2, n. 5, pp. 59-76.

Martínez, Inmaculada. (2009): “La mujer y la publicidad en España: contradicciones sociales y discursivas”, Razón y Palabra. Disponible en: http://www.razonypalabra.org.mx/libros/index.html). Consultado en febrero de 2009.

Montes, A. (2006): “Globalización y publicidad: el lenguaje universal de los perfumes", Hispanogalia. Revista hispanofrancesa de pensamiento, literatura y arte, vol. II, pp. 215-224.

Observatorio español sobre drogas (2008): Encuestas domiciliarias sobre Alcohol y Drogas en España 2007/2008. Madrid: Ministerio de Sanidad y Consumo. Disponible en: http://www.pnsd.msc.es/Categoria2/observa/estudios/home.htm. Consultado en enero de 2009.

Plaza, J. (2005): Modelos de varón y mujer en las revistas femeninas para adolescentes. Madrid: Fundamentos.

Roca, M. (2006): “La imagen de la mujer en la prensa femenina en Telva (1963-2000)”, Revista Comunicar, n. 26, pp. 149154.

Roig, M. (1989): La mujer en la historia a través de la prensa. Madrid: Ministerio de Asuntos Sociales, Instituto de la Mujer. Tseelon (1997): The masque of femininity. London: Sage.

Wimmer, R. D. y Dominick, J. R. (1996): La investigación científica de los medios de comunicación. Una introducción a sus métodos. Barcelona: Bosch. 